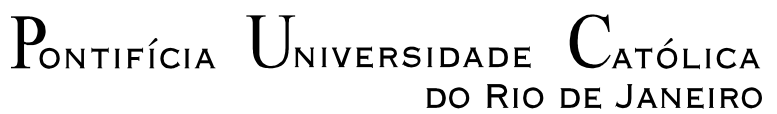

DO RIO DE JANEIRO

Daniela Rolim de Andrade

TRADUÇÃO, TRANSFORMAÇÃO E AUTORIA:

O DIREITO AUTORAL E OS ESTUDOS DA TRADUÇÃO

Dissertação de mestrado

Dissertação apresentada como requisito parcial para obtenção do grau de Mestre pelo programa de Pós-Graduação em Letras do Departamento de Letras do Centro de Teologia e Ciências Humanas da PUC-Rio.

Orientadora: Profa. Maria Paula Frota 


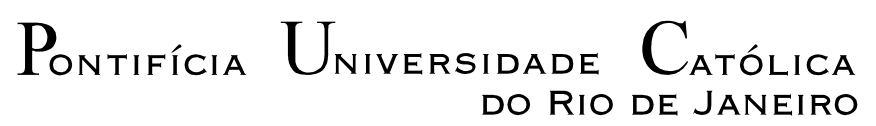

DO RIO DE JANEIRO

Daniela Rolim de Andrade

\title{
TRADUÇÃO, TRANSFORMAÇÃO E AUTORIA: O DIREITO AUTORAL E OS ESTUDOS DA TRADUÇÃO
}

Dissertação apresentada como requisito parcial para obtenção do grau de Mestre pelo programa de Pós-Graduação em Letras do Departamento de Letras do Centro de Teologia e Ciências Humanas da PUC-Rio. Aprovada pela Comissão Examinadora abaixo assinada.

\author{
Profa. Maria Paula Frota \\ Orientadora \\ Departamento de Letras - PUC-Rio
}

Profa. Marisa Gandelman

Instituto de Relações Internacionais - PUC-Rio

Prof. Paulo Fernando Henriques Britto Departamento de Letras - PUC-Rio

Profa. Denise Berruezo Portinari Coordenadora Setorial do Centro de Teologia e Ciências Humanas - PUC-Rio

Rio de Janeiro, 26 de julho de 2012 
Todos os direitos reservados. É proibida a reprodução total ou parcial do trabalho sem autorização da universidade, da autora e da orientadora.

\section{Daniela Rolim de Andrade}

É bacharel em Direito pela Universidade de Brasília (19891993). Foi bolsista, em 1998, da Fundação Rotária (Bolsas Educacionais - Rotary Foundation Ambassadorial Scholarships). Foi aluna do curso de Especialização em tradução inglês-português da PUC- Rio, na turma de 2006-7. Está inscrita na $\mathrm{OAB} / \mathrm{RJ}$, mas não advoga.

Ficha Catalográfica

Andrade, Daniela Rolim de

Tradução, transformação e autoria: o direito autoral e os estudos da tradução / Daniela Rolim de Andrade; orientadora: Maria Paula Frota. - 2012.

87 f. ; $30 \mathrm{~cm}$

Dissertação (mestrado) - Pontifícia Universidade Católica do Rio de Janeiro, Departamento de Letras, 2012.

Inclui bibliografia

1. Letras - Teses. 2. Tradução. 3. Transformação. 4. Autoria. 5. Direito autoral do tradutor. I. Frota, Maria Paula. II. Pontifícia Universidade Católica do Rio de Janeiro. Departamento de Letras. III. Título. 
Gostaria de dedicar esta dissertação à minha querida avó materna, Elba Alves Rolim, aos meus pais, Frederico José Bergamo de Andrade e Olga Rolim de Andrade, e ao meu companheiro,

Tchutchuquito. 


\section{Agradecimentos}

Agradeço a Deus, sempre.

Agradeço aos meus pais e aos meus irmãos, mas especialmente ao meu pai, Frederico José Bergamo de Andrade, pelo grande apoio afetivo e pelo suporte financeiro que me tem dado, generosamente, ao longo de todos esses anos.

Agradeço ao tchutchuco, filho gato, companheiro felino e fiel de todas as horas.

Agradeço à D. Helena e ao Sr. Emerson Jatobá (já falecido), integrantes do Rotary Clube do Recife, por meio do qual recebi uma importante bolsa de intercâmbio cultural, em 1998. Se não fosse por esta bolsa, eu certamente não estaria trilhando o caminho de agora.

Agradeço a Gláucia Pessoa, minha psicóloga por quase oito anos, e à delicadeza e humanidade da sua abordagem terapêutica. Agradeço, igualmente, ao Dr. Nelson Goldstein.

Agradeço à professora Maria Paula Frota, que me incentivou a fazer o concurso para o mestrado, uma experiência que me proporcionou um grande desenvolvimento pessoal e intelectual. Agradeço a sua atenção para comigo e agradeço o fato de termos sido minimamente pacientes uma com a outra durante os momentos mais tortuosos dessa convivência.

Agradeço às professoras Helena Martins, Marcia Martins e Maria das Graças Pereira, com quem cursei as demais disciplinas.

Agradeço ao departamento e ao programa de Mestrado em Letras da PUC-Rio, um espaço muito bem organizado e bacana de se estar. Agradeço também a Chiquinha e a Daniele pelas ajudas prestadas.

Agradeço à PUC-Rio pela generosa bolsa de isenção de pagamento oferecida a todos os alunos que ingressam no programa de Pós-graduação stricto sensu do Departamento de Letras.

Agradeço igualmente ao $\mathrm{CNPq}$ pela bolsa de apoio financeiro que me foi concedida durante o ano de 2011. 


\section{Resumo}

Andrade, Daniela Rolim de; Frota, Maria Paula. Tradução, transformação e autoria: o direito autoral e os estudos da tradução. Rio de Janeiro, 2012. 87p. Dissertação de Mestrado - Departamento de Letras, Pontifícia Universidade Católica do Rio de Janeiro.

A presente dissertação busca analisar um conceito jurídico: o de que a tradução de uma obra literária, artística e científica envolve um ato de transformação do texto original, consistindo, assim, numa (re)escrita autoral. Apresenta, brevemente, a influência do Iluminismo e do Romantismo na consolidação do direito de autor, no século XIX, quando o conceito de obra original (ou originalidade) tornou-se central nas leis que passaram a regular essa matéria. Em diálogo com Lawrence Venuti, um importante teórico da tradução, este trabalho procura verificar se a centralidade da obra original nas legislações autorais de fato contribuiu para obscurecer as traduções e, consequentemente, causar a invisibilidade do tradutor. A presente dissertação também busca encontrar fundamentos para a ideia de tradução como transformação a partir do entrecruzamento da Filosofia com os Estudos Linguísticos, explorando o assunto ainda de maneira bastante introdutória. Nesta parte do trabalho sugere-se que o aparecimento de um nova concepção de língua(gem), no final do século XVIII, foi fundamental para se passar a conceber a tradução como um ato de transformação, podendo, inclusive, ter influenciado as próprias leis da época.

\section{Palavras-chave}

Tradução; transformação; autoria; direito autoral do tradutor. 


\section{Abstract}

Andrade, Daniela Rolim de; Frota, Maria Paula (Advisor). Translation, transformation and authorship: copyrights and translation studies. Rio de Janeiro, 2012. 87p. MSc. Dissertation - Departamento de Letras, Pontifícia Universidade Católica do Rio de Janeiro.

The present dissertation analyses a legal concept: that literary, artistic and scientific translations involve an act of transformation and, for that reason, consist in an authorial (re)writing. It briefly shows the influence of the Enlightenment and Romanticism on the consolidation of the authorial rights on the nineteenth century, when the concept of original work (or originality) became central in the copyright laws. In dialogue with Lawrence Venuti, an important translation theorist, it also examines whether the centrality of the original work in the copyright legislation really contributed to obscure translation and consequently cause the translator's invisibility. The present dissertation also tries to find basis for the idea of translation as transformation through the interaction of philosophy and linguistic studies, still exploring this subject in a very introductory manner. In this part of the work, it is also suggested that the formulation of a new concept of language, at the end of $18^{\text {th }}$ century, might have been very relevant to the idea of translation as transformation, influencing the laws of that time.

\section{Keywords}

Translation; transformation; authorship; translator's copyrights. 


\section{Sumário}

$\begin{array}{ll}\text { 1. Introdução } & 10\end{array}$

2. O Direito de Autor e a Tradução 13

2.1. A consolidação do direito de autor nos séculos VIII e XIX: em meio às revoluções burguesas e ao romantismo, a emergência da propriedade privada e do gênio original nas criações artísticas

2.2. De Berna ao Brasil: um diálogo com Venuti e a análise de duas leis do século XIX: a Convenção de Berna (1886) e a lei brasileira Medeiros e Albuquerque (1898)

2.3. De Berna ao Brasil: algumas das revisões de Berna no século XX e a tradução sob o enfoque da lei brasileira de direitos autorais de 1998

Breve adendo ao capítulo 2

3. A Filosofia, os Estudos da Linguagem e a tradução como (re)escrita transformadora

3.1. A Idade Antiga, a concepção essencialista de língua e a tradução como repetição

3.2. A Idade Moderna, a concepção culturalista de língua e a tradução como impossibilidade teórica ou transformação 3.3. A Idade Contemporânea, o Estruturalismo,

o Pós-estruturalismo e o acolhimento da tradução como transformação

3.3.2. Do Estruturalismo ao Pós-estruturalismo 62

3.3.3. O Pós-estruturalismo

4. Volta à Idade Moderna: os românticos alemães e algumas de suas relevantes reflexões acerca da atividade tradutória

5. Considerações finais

6. Referências bibliográficas e bibliografia 
Sim, não somos nós frequentemente obrigados a previamente traduzir a fala de um outro que é [...] de sensibilidade e ânimo diferentes?

(Schleiermacher apud Heidermann, 2010: 39. Tradução de Celso R. Braida) 